EESTI NSV TEADUSTE AKADEEMIA TOIMETISED. 30. KOIDE GEOLOOGIA. 1981. NR. 3

ИЗВЕСТИЯ АКАДЕМИИ НАУК ЭСТОНСКОП ССР. ТОМ 30 ГЕОЛОГИЯ. 1981, № 3

удК $551.311 .234(474.2)$

Kaй BAPEC, A. РАУKAC

\title{
О ПОЧВООБРАЗУЮЩИХ ПОРОДАХ ЭСТОНИИ
}

В качестве почвообразующих пород обычно рассматривают охваченную преобразующими процессами верхнюю часть коренных пород или четвертичных отложений, которая либо непосредственно участвует в формировании почвенного профиля, либо оказывает на него косвенное влияние прежде всего путем создания специфического водного режима. Ввиду того, что почвообразующие породы определяют естественное плодородие почв и агротехнические свойства последних, разностороннее изучение их имеет немаловажное прикладное значение. Комплексное изучение состава и свойств почвообразующих пород и почв позволяет решить также ряд геологических проблем, таких как устойчивость минералов в разных физико-химических обстановках, возраст рельефа в зависимости от глубины выщелачивания карбонатов в почвенных профилях и другие.

Материнские породы Эстонии имеют ряд особенностей, обусловленных ебщим геологическим развитием территории в четвертичное время. В плейстоцене она находилась в зонах интенсивной и умеренной экзарации, вследствие чего четвертичный покров здесь сравнительно маломощен, а местами вовсе отсутствует, в частности в Северной Эстонии, где в виде почвообразующих пород нередко выступают коренные карбонатные породы (рис. 1). Кроме того, почвообразующие породы Эстонии часто являются двух- и многослойными. Обусловлено это тем, что после отступания материкового льда значительная часть территории республики была покрыта водами крупных приледниковых озер и Балтийского моря, которые накладывали свои оеадки на ледниковые отложения. Такие почвообразующие породы особенно характерны для низменной части Әстонии (рис. 2). Третьей особенностью почвообразующих пород республики является большая перемежаемость их, в частности в холмистом рельефе (рис. 1).

Из-за сложной истории развития Псковско-Чудского (Раукас, Ряхни, 1969) и Выртсъярвского (Orviku, 1973) озер, которые в прошлом имели иные размеры, а в настоящее время ввиду неравномерного неотектонического поднятия озерных впадин интенсивно продвигаются к югу, в окрестностях их широко развиты двух- и многослойные почвообразующие породы. Следует отметить, что сами ледниковые отложения также часто являются гетерогенными и многослойными. Правильное определение гомо- или гетерогенности почвообразующих пород очень важно при развитии теории почвообразования и при классификации почв. Поэтому восстановление бывших палеогеографических условий на конкретных территориях представляет для почвоведов весьма большой интерес.

Почвообразующие породы можно классифицировать по разным 

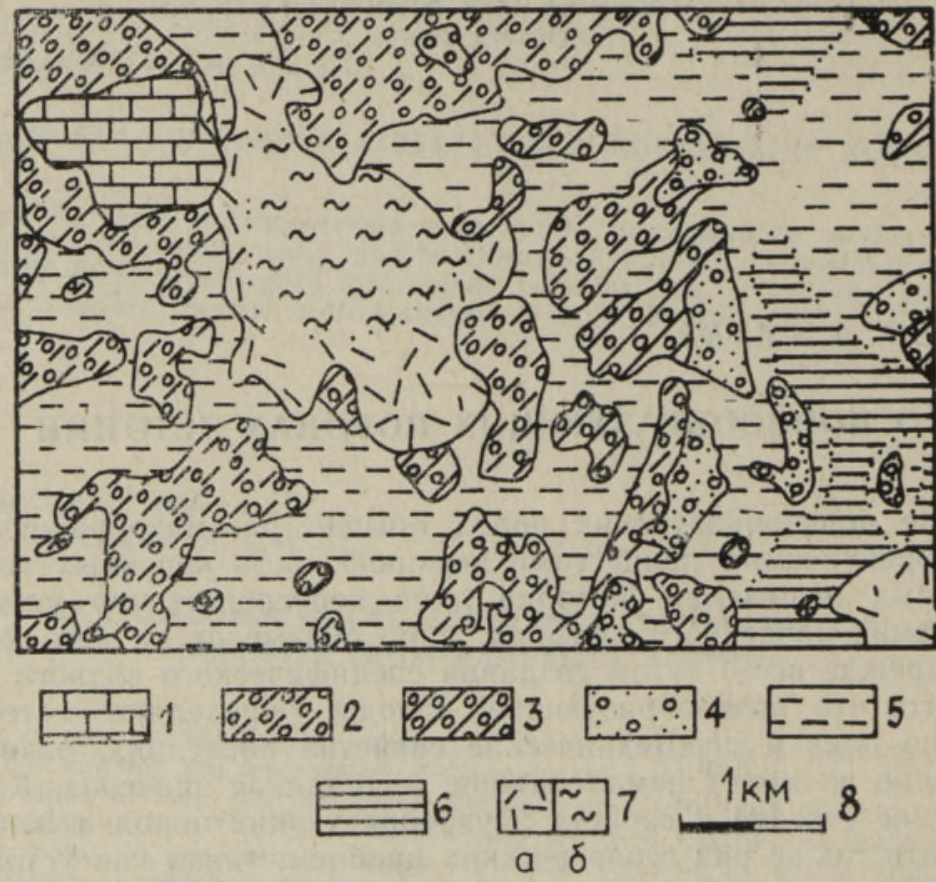

Рис. 1. Большая перемежаемость почвообразующих пород в холмистом рельєфе в окрестностях Юуру (Северная Эстония): 1 - коренные карбонатные породы, 2 - морена, 3 - морена, чередующаяся с гравийно-галечными отложениями, $4-$ флювиогляциальные гравийно-галечные отложения; $5-$ озерно-ледннковые алевриты, 6 - ленточные глины, 7 - болотные отложения $(a-$ низинный, $б-$ верховой торф), 8 - линейный масштаб.

принципам: по генезису, составу, строению и т. д. Наиболее популярными являются классификации на основе литогенетического принципа. Согласно этому принципу все встречающиеся на исследуемой территории (в данном случае на территории Эстонской ССР) почвообразующие породы целесообразно подразделить на одно-, двух- и многослойные, при этом последние два класса, разумеется, очень разнообразны. В первом приближении они могут быть подразделены на два подкласса, причем в первом подклассе в качестве нижнего почвообразующего слоя выступает верхняя часть коренных пород, а во втором четвертичных отложений.

Наиболее распространенными комбинациями в первом подклассе двухслойных пород являются морена на карбонатных породах, песчаниках, алевролитах и глинах, флювио- и лимногляциальные отложения на карбонатных породах и морские отложения на карбонатных породах, песчаниках и алевролитах, а во втором подклассе - флювиогляциальные, лимногляциальные, морские, озерные и органогенные отложения на морене, морена на флювио- и лимногляциальных отложениях, торф на озерных отложениях или озерные отложения на торфе, эоловые отложения на морских и озерных отложениях, лимногляциальные отложения на флювиогляциальных, делювиальные отложения на морене или на флювиогляциальных, лимногляциальных и органогенных отложениях. Двух- и многослойные почвообразующие породы могут быть 


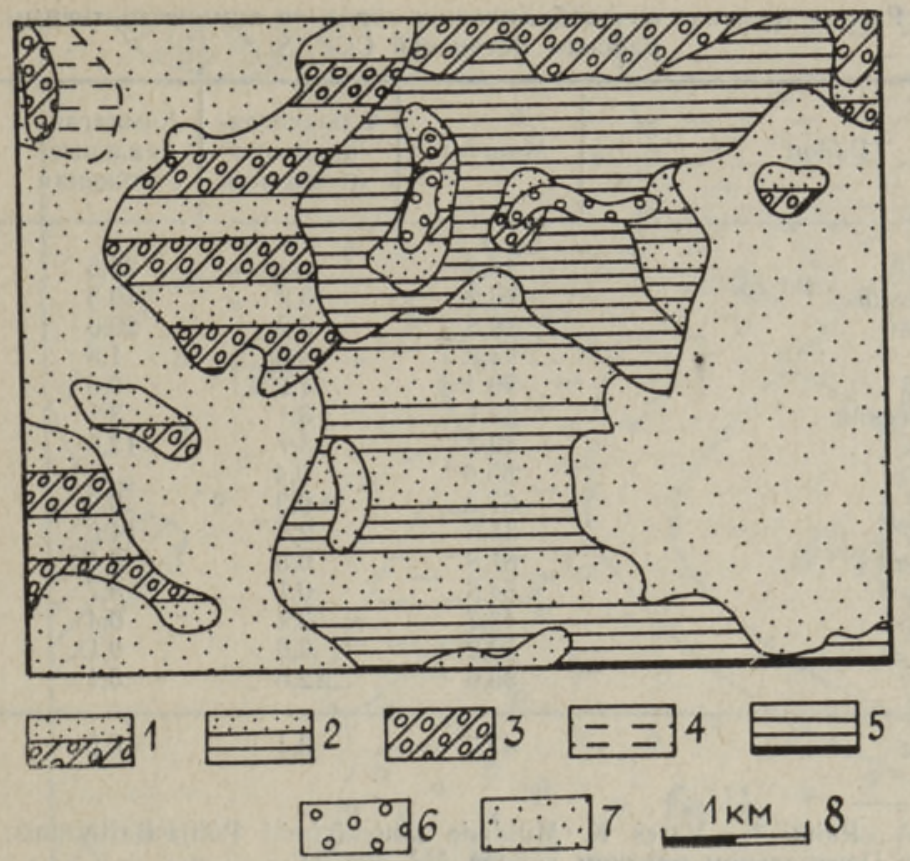

Рис. 2. Перемежаемость одно- и двухслойных почвообразующих пород на территории Матсалуского заповедника: 1 морские пески на морене, 2 - морские пески на ленточных глинах, 3 - морена, 4 - морские алевриты, 5 - ленточные глины, 6 - морские гравийно-галечные отложения (береговые валы), 7 - морские пески, 8 - линейный масштаб.

представлены также отложениями одного и того же генетического ряда, например, супесчаная основная морена на суглинистой основной морене или абляционная морена на основной морене.

Однослойные почвообразующие породы подразделяются на коренные и четвертичные. (Leet, 1968 и др.). Первые, в свою очередь, согласно укоренившимся в литологии принципам классификации, - на обломочные, глинистые, карбонатные и органогенные. При выделении подтипов обломочных пород за основу целесообразно брать разработанную в Институте геологии АН ЭССР гранулометрическую классификацию (Raukas, 1964), а при выделении подтипов карбонатных пород - разработанную в республике единую классификацию (Karbonaatkivimite ühtne klassifikatsioon..., 1965).

Среди однослойных почвообразующих пород четвертичного возраста рекомендуем выделять гляциальный, аквальный, эоловый, склоновый и органогенный генетические ряды с 13 генетическими группами, которые в дальнейшем можно подразделять на генетические типы и на фациальные разновидности. В гляциальном ряду выделяются собственно ледниковая, флювиогляциальная и лимногляциальная группы, в аквальном - аллювиальная, морская, озерная и подземноводная, в склоновом - гравитационная и делювиальная и в органогенном ряду фитогенная, зоогенная и техногенная генетические группы.

Учитывая широкое распространение двух- и многослойных почвообразующих пород и пестроту их строения (рис. $1-3$ ), точный подсчет распространения отдельных их типов очень сложен. Если упростить эту задачу и вести подсчет только по верхнему (подпочвенному) 


\section{Распространение почвообразующих пород по административным} районам Эстонской ССР, \% *

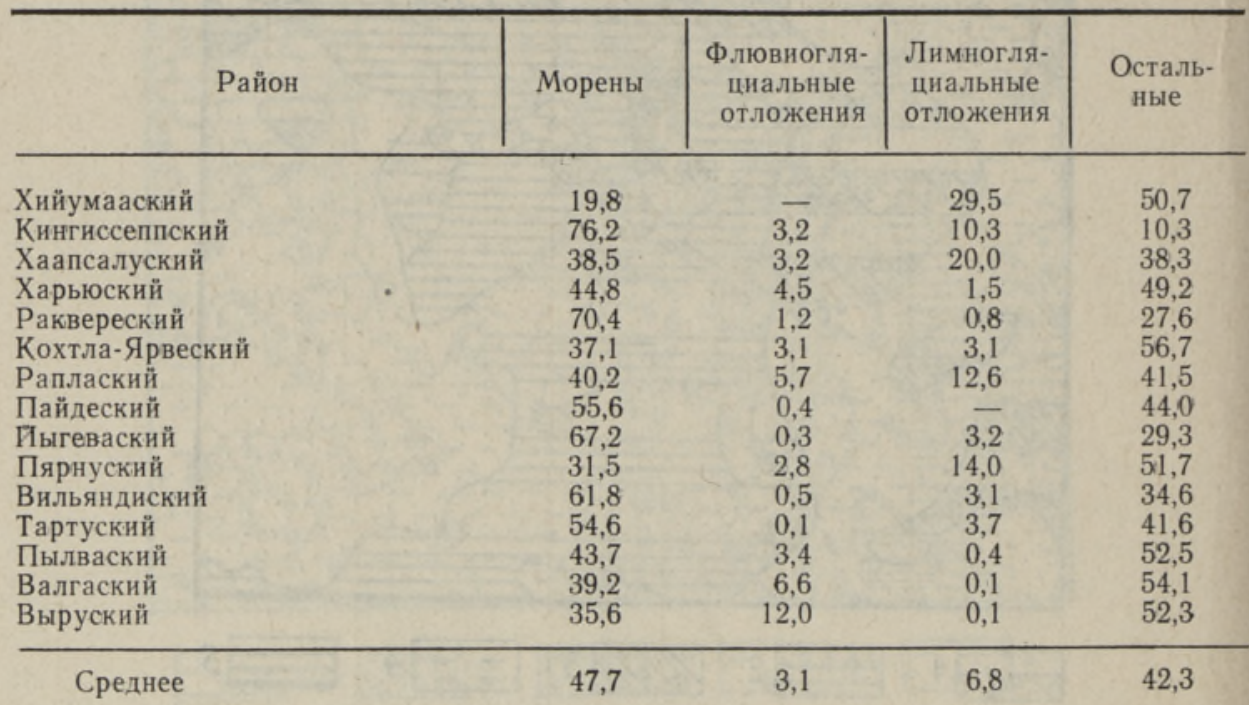

* Raukas A., Rähni E., Vares K. Muldade lähtekivimid Põhja-Baltikumis. Tln., 1974. (Рукопись в Центральном научном архиве АН ЭССР).

слою, не обращая внимания на двух- или многослойность, то выясняется, что почти половину территории республики слагают гляциальные отложения (таблица), особенно собственно ледниковые отложения - морены. Распространение последних по административным районам все же довольно неравномерное и часто очень спорадическое. На низменной части территории широко развиты морские отложения которые являются здесь преобладающими (рис. 2). Обычно они не образуют сплошного покрова, а чередуются с ледниковыми, органогенными, эоловыми и другими типами отложений.

Значительная часть территории Эстонии покрыта болотами $\left(9340 \kappa м^{2}\right.$ или $\left.20,7 \%\right)$ и озерами $\left(2130 \kappa м^{2}\right.$ или $\left.4,8 \%\right)$. Крупнейшие болота расположены в низменной части Эстонии. Меньше всего их на Пандивереской возвышенности и на островах. Основное распространение озерных почвообразующих пород связано с Псковско-Чудской и Выртсъярвской впадинами. Они широко развиты, например, к северу и северо-востоку от современного озера Выртсъярв, в районах распространения Древнего Выртсъярв (Орвику, 1958).

Bсе остальные типы почвообразующих пород развиты очень ограниченно. Хотя в Эстонской ССР насчитывается более 7000 рек и ручьев, они главным образом являются мелкими. Лишь у 420 рек длина составляет более 10 км. Из-за молодости гидрографнческой сети республики долины слабо выражены и ширина их обычно небольшая (до 200-300 м). Поэтому занятые аллювиальными отложениями площади в целом довольно скромные (рис. 3). Лишь расположенные в древних долинах реки имеют широкую террасированную пойму (например, в долине Раудна до 1,5 км). Террасы заняты в основном пастбищами и сенокосами.

Из подземноводных отложений в холмистом рельефе Южной Эстонии местами встречаются залежи травертина (Hallik, 1957; Lõokene, 1961,1968 a, б), но ввиду небольших выходов они практического зна- 

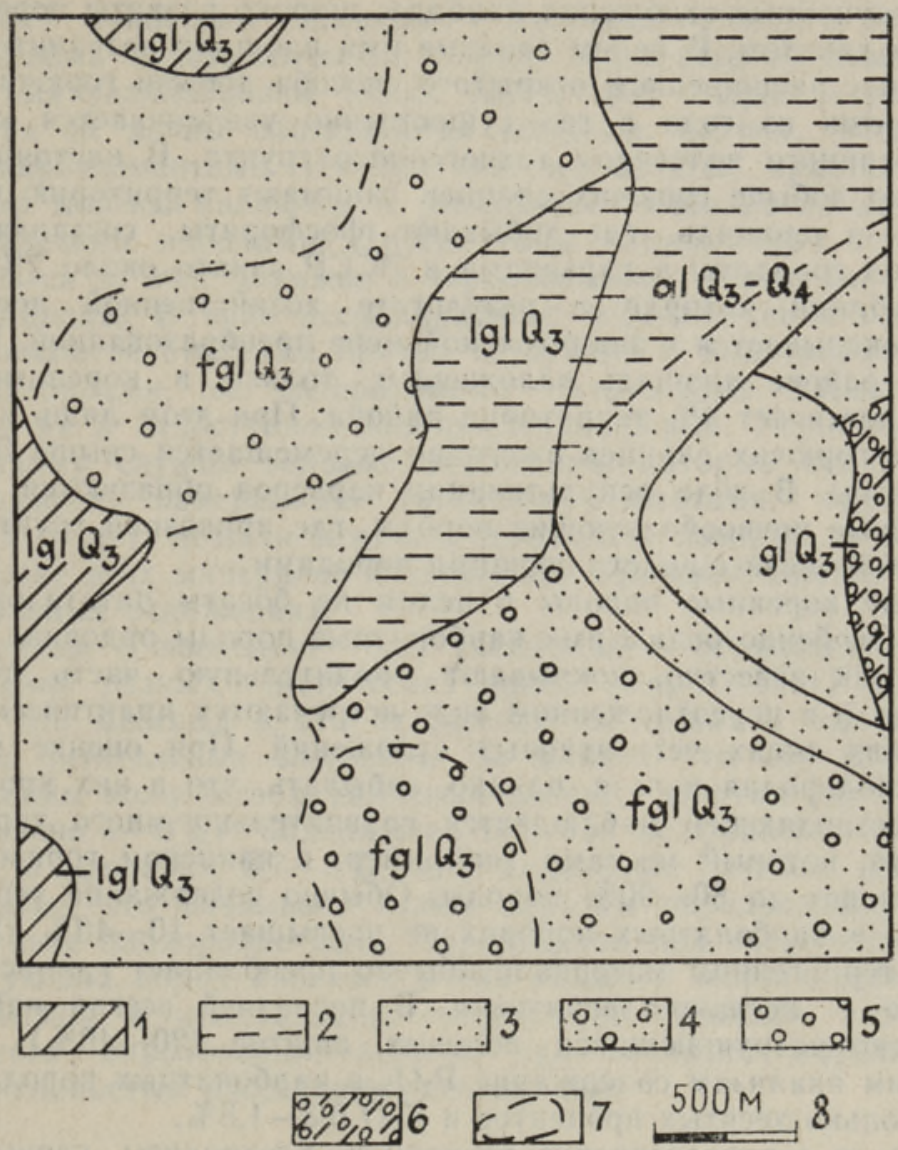

Рис. 3. Сравнительно монотонные почвообразующие породы на флювиогляциальной дельте в окрестностях Қанепи (Южная Эстония): 1 - пелитовый алеврит, $2-$ алеврит, 3 песок, 4 - гравийный песок, 5- гравий, 6 - супесчаная морена, 7 - границы литологических разновидностей, 8 линейный масштаб.

чения в качестве почвообразующих пород не имеют. Несколько шире в холмистом рельефе развиты делювиальные отложения, мощность которых достигает 1,5 м. В связи с возрастающей механизацией сельского хозяйства размеры и мощность делювиальных шлейфов быстро увеличиваются. При этом площадь эродированных участков примерно в два раза превышает площадь делювиальных образований (Kask, 1957).

Эоловые отложения встречаются в основном в виде дюн и авандюн, лишь изредка, например в Крооди, наблюдаются небольшие дефляционные равнины. Образование наиболее крупных дюн связано с трансгрессиями Анцилового озера и Литоринового моря. Кроме морского побережья они установлены также на берегу Чудского озера и в некоторых других районах (Orviku, 1933; Raukas, 1968). Из-за незначительной ширины дюнных гряд площади, занятые эоловыми отложениями, не превышают нескольких квадратных километров. Их сельскохозяйственное значение невелико. В основном они покрыты сосновым лесом, имеющим большое рекреативное значение. 
Гравитационные отложения наиболее широко развиты перед СевероЭстонским глинтом. В целом занятые ими площади незначительны.

В связи с расширением открытого способа добычи горючих сланцев и фосфоритов из года в год существенно увеличивается количество преобразованного человеком техногенного грунта. В настоящее время карьеры по добыче горючих сланцев занимают территорию более чем в $4000 z a$, а площадь, где добывают фосфориты, составляет около 800 га. Под городами и карьерами в ЭССР занято около $2 \%$ территории республики, которая в результате хозяйственной деятельности человека оказывается в значительной мере преобразованной. В КохтлаЯрвеском районе площадь заложенных только в коренные породы карьеров достигает $4 \%$ территории района. При этом лишь в карьерах по добыче горючих сланцев ежегодно перемещается свыше $50 \mathrm{млн.} \mathrm{s}^{3}$ горной массы. В ходе рекультивации карьеров образуются двух- или многослойные почвообразующие породы, где привозной грунт не имеет генетической связи с подстилающими породами.

Местные коренные породы в целом не богаты питательными элементами. Особенно бедны ими карбонатные породы ордовика и силура, которые, как известно, покрывают значительную часть территории республики и в переотложенном виде встречаются практически во всех генетических типах четвертичных отложений. При оценке их естественного плодородия нельзя, однако, забывать, что в них кроме карбонатной составляющей наблюдается сравнительно много терригенного компонента, который местами (например, в яаниском горизонте силура) составляет до $80-90 \%$ породы. Обычно содержание терригенного материала в карбонатных породах не превышает $10-40 \%$ (Юргенсон, 1970). В терригенном материале обычно преобладает глинистая фракция, реже - песчано-алевритовая. В последней всегда наблюдается много легко разрушающихся полевых шпатов $(20-40 \%)$. Судя по химическим анализам содержание $\mathrm{P}_{2} \mathrm{O}_{5}$ в карбонатных породах составляет несколько десятых процентов и $\mathrm{K}_{2} \mathrm{O}$ 0,3-1,5\%.

Средне- и верхнедевонские песчаники, алевролиты, глины, доломиты и домериты разнообразны по составу. В широко распространенных на рассматриваемой территории терригенных породах девона содержится в среднем 80-90\% кварца, 5-20\% полевых шпатов и около $5-10 \%$ слюд (Вийдинг, 1968). Выход минералов тяжелой подфракции обычно $0,5-2,5 \%$. Из легкоразрушающихся минералов в тяжелой подфракции в небольших количествах установлены апатит, амфиболы, пироксены, фосфаты и некоторые другие минералы. При этом в наровском горизонте и в низах арукюлаского горизонта среднее содержание апатита среди тяжелых минералов составляет соответственно 32 и $30 \%$ (Вийдинг, 1968).

Довольно много полезных компонентов содержится в терригенных породах венда, кембрия и низов ордовика, но эти породы имеют относительно ограниченное распространение, обнажаясь в нижней части глинта и в предглинтовой области. Указанные породы относительно богаты полевыми шпатами (до $30 \%)$, глауконитом (в низах лонтоваской свиты до $10-20 \%$, в латорпском горизонте местами свыше $50 \%$ ) и фосфатами (особенно в пакерортском горизонте, где встречаются промышленные месторождения оболовых фосфоритов). Естественное плодородие почв близ глинта повышают также встречающиеся в тюрисалуской пачке богатые разными микроэлементами диктионемовые аргиллиты, содержащие около $6-8 \% \quad \mathrm{~K}_{2} \mathrm{O}, 0,1-0,2 \% \quad \mathrm{~V}_{2} \mathrm{O}$ и $0,2-0,6 \% \quad \mathrm{P}_{2} \mathrm{O}_{5}$.

Наибольшие запасы питательных элементов почв на территорию 
Эстонской ССР принесены ледниками с Балтийского щита в виде валунов и мелкозёма кристаллических пород. Последние по химическому составу весьма разнообразны (Kask, Niine, 1971 и др.). В результате выветривания их почвы обогащаются железом, калием, фосфором и многими микроэлементами. Именно поэтому богатые кристаллическими породами морены являются в республике наиболее плодородными почвообразующими породами. Другие типы четвертичных отложений, образовавшиеся за счет размыва и переотложения морен, как правило, менее плодородны. В ходе неоднократного переотложения они постепенно обогащаются стойкими против истирания и выветривания породами и минералами, не содержащими питательные элементы или содержащие их в недоступной для растений форме. Хорошим примером сказанному служат эоловые отложения, которые беднее легкоразрушающимися минералами (полевыми шпатами, пироксенами, амфиболами и др.), нежели морские отложения, которые, в свою очередь, содержат этих минералов меньше, чем это наблюдается в исходных гляциальных отложениях.

Выполненные в последние годы специальные исследования песчаных отложений разных генетических типов (Варес, 1981) позволяют заключить, что местами и эти отложения содержат в значительных количествах питательные элементы. Во многом это обусловлено довольно высоким количеством калиевых полевых шпатов (до 15-20\%) и слюд (обычно $1-3 \%$ ). Содержание тяжелой подфракции чаще всего колеблется в пределах $0,7-3 \%$, а в отдельных случаях его значительно больше, что оказывает таким образом определенное влияние на естественное плодородие почв. Характерной для песчано-гравийных почвообразующих пород является очень большая изменчивость в гранулометрическом и минеральном составах по площади, что требует более густого опробования, нежели при изучении моренных или алевритово-глинистых бассейновых отложений.

\section{Л ИТ Е РАТ У РА}

В а ре с К. О составе песчано-гравнйных почвообразующих пород Эстонни. - В кн.: Новые методы в геологии Эстонии. Таллин, 1981.

В и й дин г Х. А. Литолого-минералогический состав и вопросы генезнса терригенных отложений девона Северной Прибалтики. - В кн.: Генезис и классификация осадочных пород. М., 1968, $75-81$.

Ор в и ку Л. Ф. Новые данные по геологии озера Выртсъярв. - Тр. Ин-та геологии АН ЭССР, 1958, 3, 269-293.

Р а ук а с А., Р яхн и Э. О геологическом развитии впадины и бассейнов Чудского и Псковского озер. - Изв. АН ЭССР. Хим. Геол., 1969, 18, 113-127.

Юргенсон Э. Распределение и состав терригенного материала. - В кн.: Силур Эстонин. Таллин, 1970, 68-96.

$\mathrm{H}$ allik, O. Magevee lubjalasundid Eesti NSV-s ja nende kasutamine. Tln., 1957.

Karbonaatkivimite ühtne klassifikatsioon ja legend. Tln., 1965.

K a s k, R. Muldade erosioonist Eesti NSV-s. - Eesti Geograafia Seltsi aastaraamat 1957. TIn., 1957, 115-135.

$\mathrm{K}$ a s k, R., N i i n e, H. Eesti NSV muldade lähtekivimi põhiliste komponentide keemilisest koostisest. - EMMTUI teaduslike tööde kogumik. Tln., 1971, 22, 3-26.

Leet, R. Eesti muldade lähtekivimid. - Rmt.: Mullastiku kaardistamise välitööde metoodika. (EPA väljaanne.) Tartu, 1968, 78-86.

Lōokene, E. Allikalubja geoloogiast Eesti NSV-s. - ENSV TA Geoloogia Instituudi Uurimused, 7, 135-145.

Lõokene, E. Allikalubja levik ja iseloom Haanja kõrgustikul. - TRU toimetised. Töid geoloogia alalt. Tartu, 1968a, 213, 3-33.

Lõoken e, E. Allikasetete levik ja iseloom Otepää kõrgustikul. - TRU toimetised. Töid geoloogia alalt. Tartu, 19686, 213, 34-57.

Orviku, K. Tuiskliiv. Tartu, 1933. 
O rviku, K. Vōrtsjärve geoloogilisest arengust. - Rmt.: Vōrtsjärv. Tln., 1973, 26-32. $\mathrm{R}$ a u k a s, A. Purdkivimite terasuuruse klassifikatsioon. Tln., 1964.

R a u k a s, A. Eesti luiteliivade koostisest ja kihilisusest. - Eesti Geograafia Seltsi aas. taraamat 1966. Tln., 1968, $72-88$.

Институт геологии

Академии наук Эстонской ССР
Поступила в редакцию 27/XI 1980

Kai VARES, A. RAUKAS

\section{EESTI MULDADE LĂHTEKIVIMID}

Eesti maa-ala geoloogilise arengu omapära tōttu on muldade lähtekivimid sageli kaheja mitmekihilised. Valdavad lähtekivimid on liustikusetted, Madal-Eestis ka meresetted. Siin on suuri piirkondlikke erinevusi (vt. tabel). Artiklis on lähtekivimid jaotatud kolme klassi - ühe-, kahe- ja mitmekihilised. Uhekihiliste lähtekivimite seas on eristatud aluspõhjalisi ja pinnakattelisi. Esimesed on jaotatud purd-, savi-, karbonaat- ja organogeenseks rühmaks, teised liustiku-, vee-, tuule-, raskusjõu- ja elutekkeliseks reaks 13 geneetilise rühmaga. Kohalikes aluspōhjakivimites on toiteelemente suhteliselt vähe. Kōige rohkem leidub neid moreenides, milles on rohkesti kristalseid rändrahne. Viimaste lagunedes rikastub muld raua, kaaliumi, fosfori ja paljude mikroelementidega. Moreenil on kujunenud Eesti kõige viljakamad mullad. Setete läbipesemisel ja korduval ümberpaigutumisel suureneb neis porsumisele vastupidavate mineraalide ja kivimite hulk, mistôttu liustiku sulamisvee tekkelised setted on toitainetevaesemad kui moreenid ja meresetted omakorda vähem viljakad kui liustiku sulamisvee setted. Toiteelementide poolest kōige vaesemad on meresetetest kujunenud tuuletekkelised setted.

Kai VARES, A. RAUKAS

\section{THE ESTONIAN SOIL-FORMING ROCKS}

Two-layered and many-layered soil-forming rocks are rather frequent due to the peculiarities of geological development of Estonian territory. In Estonia, carbonate bedrock serves as parent material more often than in the neighbouring areas. Glacial deposits are the prevailing soil parent materials; however, in Low-Estonia, marine deposits are also rather frequent. Parent materials show great differences in the regional distribution.

The authors divide all soil-forming rocks into three classes (one-, two- and manylayered); the last two classes are, in turn, divided into two subclasses. Bedrock and surficial deposits are distinguished among one-layered rocks. The former are divided into clastic, clayey, carbonaceous and organogenic groups, while the latter form glacial, fluvial, eolian, gravitational and organogenic rows with thirteen genetic groups.

The local bedrock material is rather poor in feeding elements. They are more abundant in tills rich in crystalline boulders. With the weathering of the latter, soils have become enriched with iron, potassium, phosphorus and several microelements. The most fertile soils in Estonia have developed on tills. As a result of the outwash and displacement of deposits the amount of weathering-resistant minerals and clasts grows in them. In consequence of the action of glacial melt waters, the fluvioglacial deposits are poorer in feeding components than tills, and marine deposits, in turn, are less fertile than the fluvinglacial deposits. Eolian deposits, developed on the basis of marine deposits, are usually the poorest in feeding elements. 